\title{
On a pile in which the attackable electrode is of coke
}

\section{P. Jablochkoff}

To cite this article: P. Jablochkoff (1878) On a pile in which the attackable electrode is of coke, Philosophical Magazine Series 5, 5:28, 76-77, DOI: 10.1080/14786447808639391

To link to this article: http://dx.doi.org/10.1080/14786447808639391

曲 Published online: 13 May 2009.

Submit your article to this journal ๘

Џ Article views: 2

Q View related articles ¿ 
as I have shown, in the atmosphere of the hearth. The cooling and extinction of the gases stops all reaction; and when the latter are thrown off by the chimney they still contain, as we see, large quantities of combustible materials.

The investigations which I have made for the purpose of taking up a portion of these gases, left hitherto unused, have demonstrated that it is easy to rekindle them by passing them over a fire, at the same time retarding their motion. It was with this view that, in my forges at Saint-Marc (Côte d'Or), I had a furnace of large dimensions set up to receive the gases as they issued from the generator. On arriving in this furnace, the section of which is more than 3 square metres, the gases lose a large portion of their velocity, at the same time that they are kindled in passing over a small grating on which coal-cinders, or some combustible of small value, are burned.

The high temperature developed in these conditions is utilized in my works for the annenling of sheet-iron. It is, in fact, known that rolling renders the iron brittle, and that it becomes covered with adherent oxide in the annealing-ovens. By heating the sheets thus altered for twelve hours in cast-iron boxes well closed, arranged in the gas-oven just mentioned, the sheets are found, after complete cooling, to have become perfectly malleable; and the oxide has disappeared, leaving the surfaces clean and bright. This reduction is easily explained if we remember the beautiful researches of MM. H. Sainte-Claire Deville and Troost on the passage of hydrogen through red-hot metals. I have likewise had the honour to communicate to the Academy* various experiments which prove that, on plunging a flattened iron tube into a fire, hydrogen passes through its sides, and, accumulating within it, causes it to resume its original form. The gases which have penetrated into the cast-iron box under the influence of the red-hot sides are therefore essentially reducing, and produce in a very short time complete deoxidation of the metallic surfaces.

In brief, we may conclude from my experiments :-

1. That the gases issuing from metallurgic fires still contain, even after passing under steam-generators, an important quantity of combustible principles, and that, with the aid of the processes above described, it is easy to kindle them afresh and burn them almost completely.

2 . That the passage of reducing gases through the red-hot metallic walls is capable of receiving applications in metallurgy which doubtless will not be limited to the particular case of which I have given an account.-Comptes Rendus de l'Académie des Sciences, Nov. 19,1877 , tome 1xxxv. pp. 955-957.

ON A PILE IN WHICH THE ATTACKABLE ELECTRODE IS OF COKE. BY P. JABLOCHKOFF.

The coke burned in steam-engines produces work which, trans* Comptes Rendus, t. lviii. pp. 327, 1057. 
formed into electricity by means of magneto-electric machines, supplies this electricity much more economically than any chemiculaction pile that has hitherto existed. This consideration gave me the idea of producing electricity by attacking coke directly. But, as every one knows, coke is not attacked by any liquid at ordinary temperatures; I was therefore obliged to construct an electrochemical pile with hot liquid.

Now it was evident that bodies which are liquid at ordinary temperatures would be vaporized at the temperature necessary for attacking coke. Hence it was necessary to take a substance which would only become liquid at a sufficiently elevated temperature, and be converted into vapour only at a very high temperature.

With this view I fused either nitrate of potass or nitrate of soda; and in this liquid I immersed as attackable electrode ordinary coke, and platinum as the unattackable electrode. But experience has proved to me that this latter electrode may be iron, cast iron, or any other metal which in the presence of coke is not attacked by the liquid.

By adding different metallic salts one can vary the electromotive force of the pile, the velocity of combustion of the coke; and with those salts the galvanoplastic deposit of the metals is received upon the unattackable electrode.

The electromotive force of the pile varies between 2 and 3 units, according to the nature of the metallic salts introduced into the liquid; this force is therefore superior to that of either the Bunsen or the Grenet pile; indeed the Bunsen pile gives the maximum of 1.8 unit, the Grenet pile 2 or, in the most favourable conditions, $2 \cdot 1$ units.

To set the pile in action in the most practical manner, it is not necessary to fuse the alkaline nitrate beforehand; it suffices to ignite a piece of coke and put it in contact with the nitrate in powder. Chemical action commences immediately; the temperature produced fuses the salt which surrounds the coke; and the pile enters upon its functions. During the activity of the pile much carbonic acid and other gases are liberated. I have devised an arrangement permitting the gas to be stored, in order to make it serve as a motive power. The following is the practical arrangement of the elements of the pile:-

A cast-iron pot, of a cylindrical shape, serves at the same time as receiver and unattackable electrode. An iron-wire basket, of concentric form, serves for holding the coke, and at the same time plays the part of a rheophore. As the coke and fused salt are consumed, fresh quantities of both substances can be added by hand, or the pile can be fed automatically, during the whole time of the operation. Contrary to what might have been thought, the combustion is not at all rapid.

Therefore, by this process, direct combustion of coke gives the electric current, the deposition of metals, and a motive power.Comptes Rendus de l'Académie des Sciences, Dec. 3, 1877, tome lxxxv. pp. 1052, 1053. 